\title{
Neuer Messeverbund beschert hohen Besucherzuwachs
}

\author{
In hohem Maße profitierte die diesjährige Parts2clean vom ersten gemeinsamen Messeauftritt
} mit der O\&S. Nach Angaben des Veranstalters stieg das Besucheraufkommen gegenüber dem Vorjahr um fast 70 Prozent auf 8460 Fachbesucher.

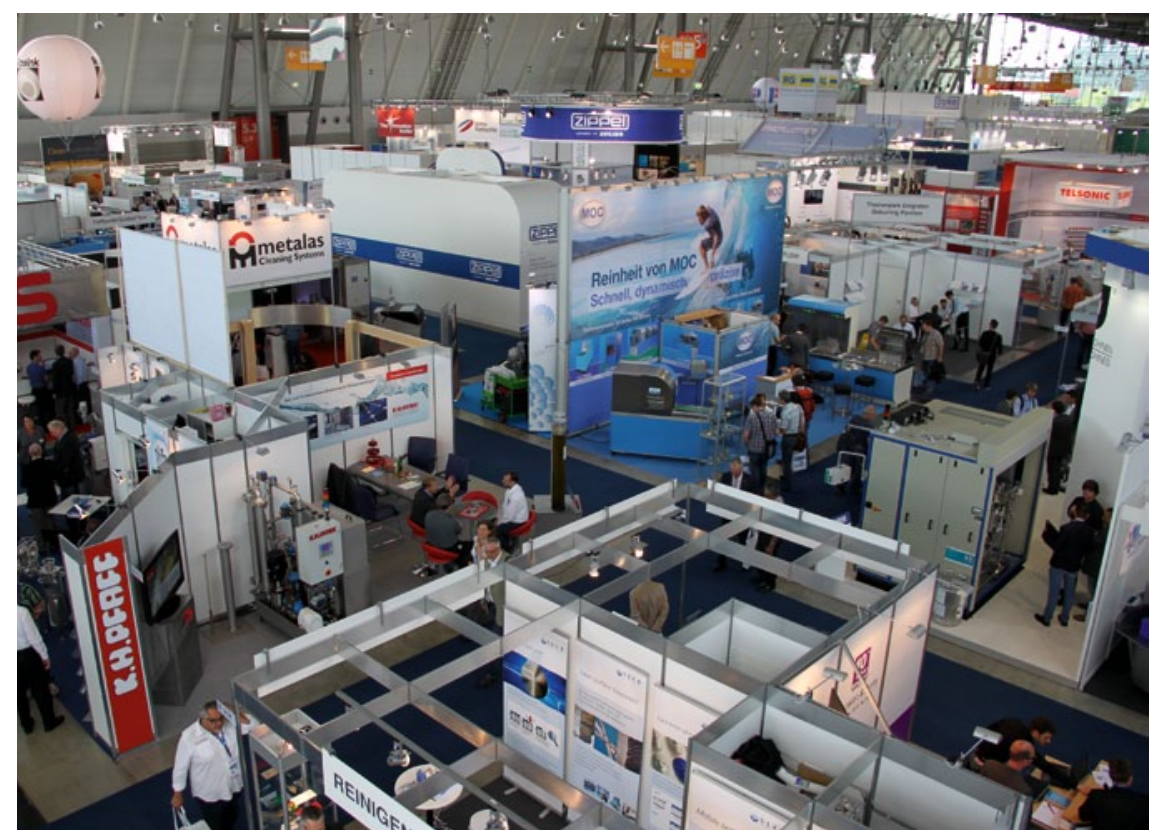

$\mathrm{D}$ ie Parts2clean - internationale Leitmesse für industrielle Teile- und Oberflächenreinigung - wurde vom 24. bis 26. Juni 2014 erstmals zeitgleich mit der O\&S, der internationalen Fachmesse für Oberflächen und Schichten, ausgerichtet. Nach Angaben der Deutschen Messe AG kamen ins-

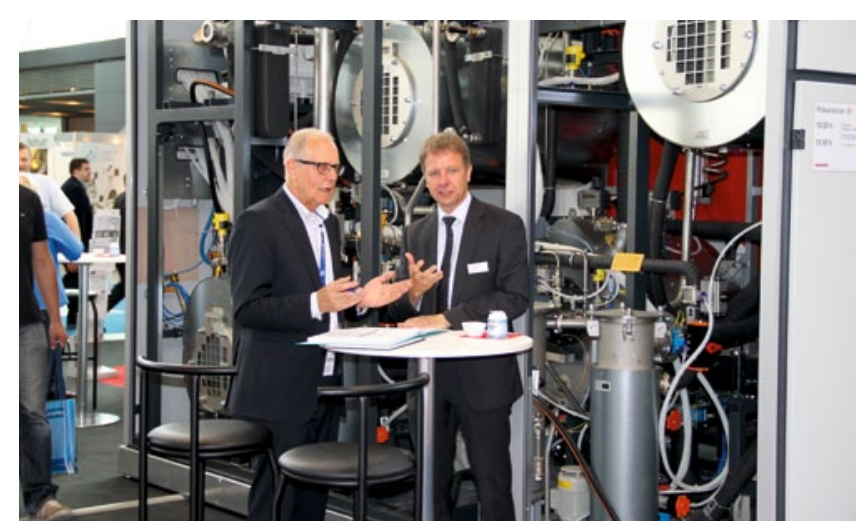
garter Messegelände. 62 Prozent der O\&S-Besucher nutzten demnach die gungstechnik auf der Parts2clean zu informieren. Laut Veranstalter ergab die Besucheranalyse der Parts2clean damit insgesamt ein Ergebnis von 8460 Fachbesuchern, was einem Wachstum von knapp 70 Prozent entspricht. Der Anteil ausländischer Besucher lag bei 21 Prozent (2013: 20 Prozent). Sie kamen aus 33 Ländern.

Insgesamt präsentierten auf der Parts2clean 269 gesamt 10916 Besucher auf das StuttMöglichkeit, sich auch über Reini-
Unternehmen (265 im Vorjahr) aus 14 Ländern Produkte und Dienstleistungen für die industrielle Teilereinigung. Mit 6627 Quadratmetern verzeichnete die Fachmesse 2014 ein Plus von gut vier Prozent bei der Nettoausstellungsfläche.

Auch in diesem Jahr wurden von den Ausstellern wieder die fachliche Qualifikation und die hohe Entscheidungskompetenz der Messebesucher gelobt: 86 Prozent gaben an, in betriebliche Investitionsprozesse eingebunden zu sein, 51 Prozent kamen mit konkreten Investitionsabsichten auf die Parts2clean.

Umgekehrt waren auch die Besucher mit dem Angebot der Aussteller zufrieden. 94 Prozent der Befrag-

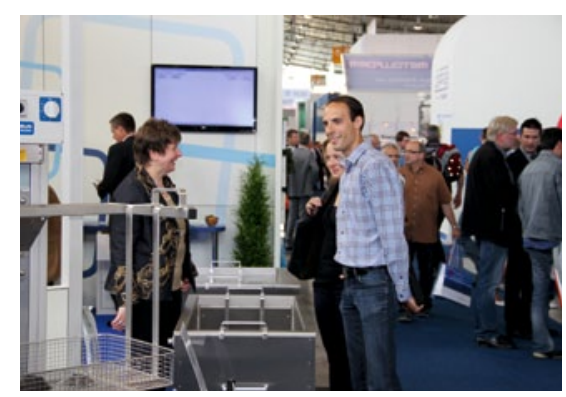

ten würden die Messe weiterempfehlen. Und rund 60 Prozent der Befragten gaben an, einen erneuten Besuch fest einzuplanen.

Der jährliche Veranstaltungszyklus der Parts2clean soll nach Aussage von Olaf Daebler, Geschäftsleiter der O\&S und Parts2clean bestehen bleiben. Die nächste Parts2clean ist für 9. bis 11 . Juni 2015 geplant. Dann allerdings ohne O\&S, die erst wieder 2016 stattfinden wird. I 